\title{
Understanding the impact of a new Pharmacy Sore throat Test and Treat service on patient experience: A quantitative study
}

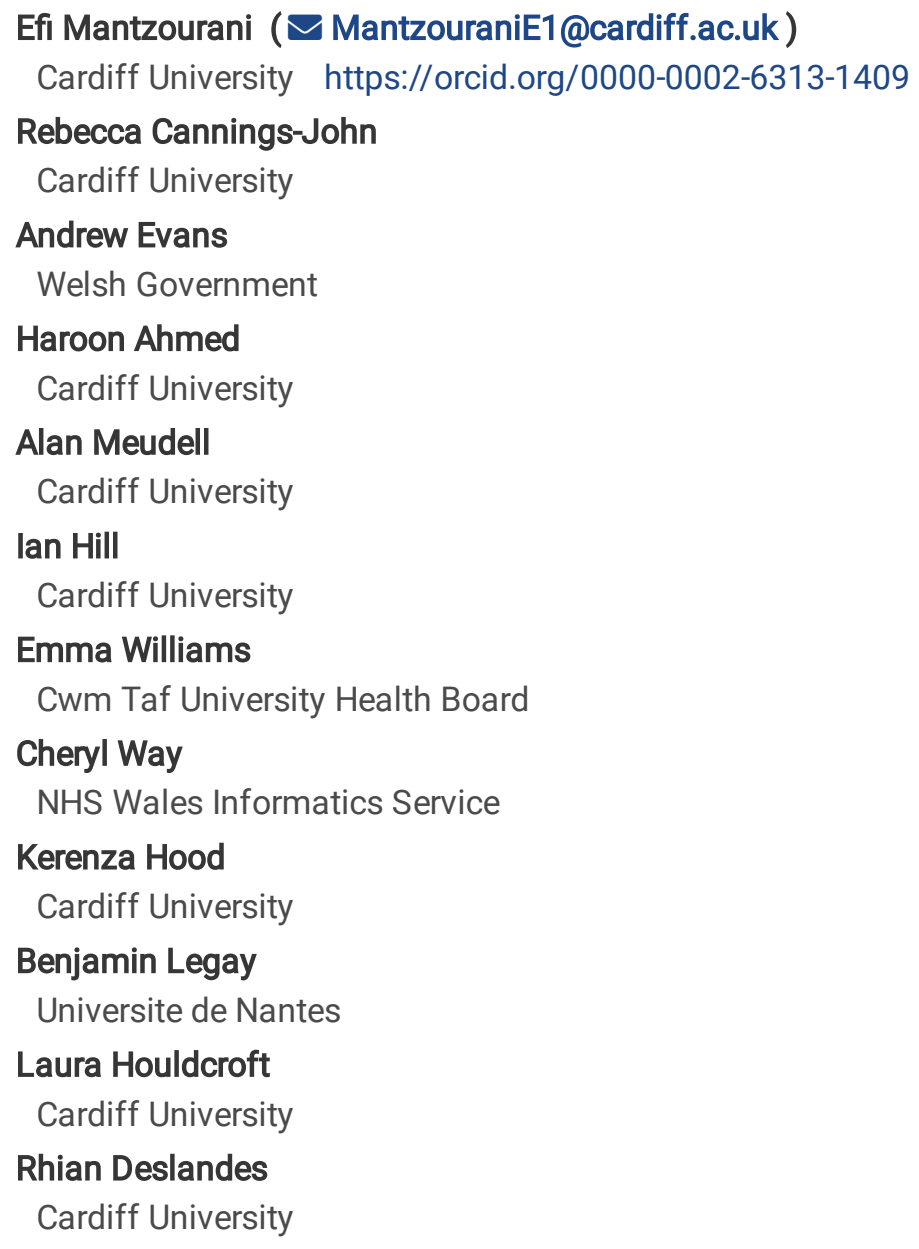

Research article

Keywords: Community pharmacy services, sore throat test and treat, patient acceptability, patient experience, health-seeking behaviour change, minor ailments, common ailments, extended pharmacy roles, Choose Pharmacy

Posted Date: February 21st, 2020

DOI: https://doi.org/10.21203/rs.2.24218/v1

License: () (1) This work is licensed under a Creative Commons Attribution 4.0 International License. Read Full License 


\section{Abstract}

Background : A pilot of the first NHS funded Sore Throat Test and Treat (STTT) service in the United Kingdom began in selected community pharmacies in Wales in November 2018. The aim of this research was to explore whether a pharmacist delivering consultation for sore throat that included clinical scoring and point-of-care testing was acceptable to patients, and how this might influence future health-seeking behaviour for subsequent sore-throats.

Methods : Quantitative research was employed, with a non-experimental design using a survey research tool including a mix of closed and open questions, developed in collaboration with members of the public. The patient experience survey was distributed to all patients who had completed a consultation between November 2018 and May 2019. Data from completed surveys were entered in Jisc Online Surveys $\AA$ and exported to Excel ${ }^{\circledR}$ for descriptive statistics. Free-text comments were analysed using content and inductive thematic analysis.

Results : A total of 510 surveys were received from 2,839 sore throat consultations (response rate 18\%). Overall, 501 patients $(98 \%)$ were satisfied with the service. Patients' confidence in managing their condition and service satisfaction was not dependent on having been supplied antibiotics. A total of 343 patients (67\%) requested a GP appointment but were offered to a consultation in the pharmacy. After the service, 504 patients (99\%) stated that they would return to the pharmacy for subsequent sore throat symptoms. Inductive analysis of free-text comments $(n=242)$ revealed 3 themes: convenience and accessibility; professionalism of pharmacy team; and perceived value of the service.

Conclusions : Results confirmed high levels of patient satisfaction with the new service, the way it was delivered and the increased choice of options for sore throat symptom management it offered. Whilst this research can only discuss patients' reported future behaviour, the patient-reported stated intentions signify a potential shift in health-seeking behaviour towards a pharmacist-led service. This has important implications in supporting the long term plan of the governments in Wales and England to redirect management of uncomplicated conditions from GPs to pharmacies.

\section{Background}

The Welsh Government (WG) have recently published their vision for "A Healthier Wales". This places renewed emphasis on supporting people to live independently, with sustainable services that are delivered closer to home when appropriate and supported by the right healthcare professionals, in line with principles of Prudent Healthcare [1]. The National Health Service (NHS) England Long Term plan describes a similarly ambitious vision [2]. A key enabler to delivering these strategies is ensuring that primary care services are rebalanced so that uncomplicated management of minor ailments and chronic conditions is shifted to community pharmacies, creating more accessible pathways for patients and giving GPs more time to manage more complex conditions and patients. Current evidence suggests that compared to GP consultations, pharmacy consultations for minor ailments are associated with similar health-related outcomes and substantially lower costs [3].

However, there are barriers to delivering such a strategy through community pharmacy. A recent systematic review concluded that patients and the public appeared to view the expanding role of pharmacists as beneficial, but highlighted that more research is needed to understand how community pharmacies are held within the mindset of patients and the public, and explore different approaches to increase awareness of pharmacist skills [4]. This becomes crucial when a complex intervention is being introduced such as a new service in community pharmacies, where exploring acceptability with patients as a key stakeholder group becomes paramount to successful implementation [5].

The management of patients presenting to primary care with uncomplicated sore throat is one area where care could be transferred from GPs to community pharmacists supported by the use of point-of-care testing (POCT). The use of POCT in community pharmacy has been explored by Buss et al. and identified as useful for supporting pharmacists' decision-making [6]. Several schemes have been piloted in the UK and internationally whereby sore throat management in the community pharmacy is being augmented by POCT [7-10], but there is little research reporting the experience of patients who use such schemes. The pilot of the first NHS funded Sore Throat Test and Treat (STTT) service in the UK was introduced in selected community pharmacies in Wales in November 2018. A recent study evaluating pharmacists' perceptions of the scheme revealed high levels of acceptability and satisfaction [11]. The service adopted a staged test and treat strategy, with pharmacists using clinical scoring tools

Page 2/18 
(FeverPAIN and CENTOR) to complete an initial examination, offering a POCT to screen for the presence of Streptococcus A if threshold scores were met, and antibiotics, if needed, in the case of a positive POCT.

The aim of this study was to explore patient views of the STTT service using a methodology co-designed with patient researchers. We particularly wanted to explore whether the use of a clinical score and POCT by pharmacists was acceptable to patients, and to understand their likely future health-seeking behaviour regarding consulting at the pharmacy rather than the GP with sore throat. This research was needed to assess the impact of the initial phases of the service on the patient experience and generate new knowledge to inform policy around further roll-out.

\section{Methods}

To achieve the aim of this study a positivism paradigm was employed. We used quantitative research and a non-experimental design, with a survey research tool, distributed to patients between November 2018 and May 2019.

\section{Patient and Public Involvement}

Representatives from the Cardiff School of Pharmacy and Pharmaceutical Sciences Lay Faculty (AM and IH) are actively involved in all aspects of this research. In line with the UK Standards for Public Involvement, we have collaboratively reflected on improved ways to engage them in the research [12]. Learning from their involvement has been included in this report.

In preparation for conceptualising the patient experience survey, all members of the lay faculty were equally invited to become involved. AM and IH responded and the survey was designed in collaboration with them. They advised on a number of questions and language, so that the final readability score of the document, using the Flesch Reading Ease and Flesch-Kincaid Grade Level readability tests, were within the desired ranges [13]. Advice was provided on the research protocol submitted to Research and Development departments, in particular regarding the best approach for distributing the survey (including time and setting), and options for online completion.

Both members of the lay faculty also led the write up of the lay summary for this report, contributed to the background and rationale for the study, and advised on dissemination and certain aspects of methodology. We ensured access to video/phone conference facilities, to enable remote attendance to meetings, where needed. They helped ensure our research recommendations are meaningful for patients.

The GRIPP2 guideline was followed when writing the study report and the GRIPP2 short checklist has been completed (Supplementary Table 1).

\section{Research Instrument}

A participant information sheet and patient experience survey were developed in collaboration with lay members of the public. The survey included three main parts: closed questions in relation to a) the service, for which patients had to state their level of agreement based on a 5-point Likert scale (1:strongly disagree, 5: strongly agree), b) background information on patient demographics, action already taken before coming to the pharmacy and future intentions in relation to seeking help from a healthcare professional for sore throat symptoms, and c) an open-ended question available at the end of the survey to allow patients the opportunity to explain answers and provide information that may help support the quantitative data collected [14]. A copy of the survey in English and Welsh is provided in Supplementary Figs. 1 and 2.

For patients under 12, the parent or carer was asked to fill in the survey on their behalf. For patients between 13 and 18 , the choice was available for either the patient to fill in the survey themselves or a parent/carer on their behalf, in line with the Gillick competence guidance [15].

The survey was piloted with five members of the public. A Welsh version of the study documents was available, and electronic links for online completion were available to increase patient options [16-17] in both English and Welsh [18].

\section{Study Population}


The implementation of the STTT service started in November 2018 with 23 pharmacies in one Local University Health Board (LHB) in Wales. Another 33 pharmacies started providing the service in a second LHB by January 2019. A detailed description of the patient journey through the service is presented in Fig. 1. Total population purposive sampling was employed in this research: patient experience surveys were handed out by pharmacists to all patients who were eligible for the STTT service, had presented to one of the 56 participating pharmacies and had completed the consultation, regardless of the outcome. Patients could complete the survey in the premises and use a pre-paid envelope to either post directly to the research team or hand back to the pharmacist to post, or complete the online version of the survey. Participant consent was implied upon return of the completed survey.

***Insert Fig. $1^{\star \star *}$

\section{Analysis}

All responses from completed surveys were entered in Jisc Online Surveys ${ }^{\circledR}$ and exported to Microsoft Excel ${ }^{\circledR}$ for descriptive statistics. Responses in Welsh were translated by a Welsh speaker before entering into a spreadsheet. A $10 \%$ validation check was completed to quality assure the data transfer. Free-text comments were imported to Microsoft Word $\circledast$ and content as well as inductive thematic analysis was used. Survey responses for questions with missing values were adjusted to account for different data available and missing values were reported. Responses to Likert type questions were summarised using counts and proportions. Characteristics (age, gender, tried to see a GP before) of patients who attended a STTT consultation within the same period were obtained from Choose Pharmacy, the national IT platform via which services are recorded in community pharmacies in Wales. Since the Choose Pharmacy data were anonymised, the patients responding to the survey data could not be identified in this dataset to enable us to describe two mutually exclusive samples (patient responding to the survey versus patients that did not). However, this still enabled a comparison of the population of patients returning a completed survey with the total population of patients receiving an STTT consultation.

\section{Results}

A total of 510 completed surveys were received by the end of the data collection period (510 out of 2,839 consultations, response rate $18 \%$ ) (English $n=499$, Welsh $n=11$ ). No surveys were returned electronically. Table 1 compares patient demographics of the survey responders with the whole population who have received a STTT consultation in a community pharmacy participating in the pilot, during November 2018 to May 2019. The age and gender distributions are similar between the two populations, but a greater proportion of those responding to the survey had seen their GP previously. 
Table 1

Patient demographics and background information for patients completing the survey and those who received a Sore Throat test and Treat (STTT) consultation

\begin{tabular}{|c|c|c|c|c|c|}
\hline & & \multicolumn{2}{|c|}{$\begin{array}{l}\text { Patients completing the } \\
\text { survey } n=510\end{array}$} & \multicolumn{2}{|c|}{$\begin{array}{l}\text { Patients receiving an STTT } \\
\text { consultation } n=2839\end{array}$} \\
\hline & & $\mathrm{n}$ & $(\%)$ & $\mathrm{n}$ & $(\%)$ \\
\hline \multirow[t]{10}{*}{ Age (years) } & $<12^{\star}$ & 71 & $(14.7)$ & 426 & $(15.0)$ \\
\hline & $13-18$ & 68 & $(14.1)$ & 520 & $(18.3)$ \\
\hline & $19-24$ & 73 & $(15.1)$ & 378 & $(13.3)$ \\
\hline & $25-34$ & 103 & $(21.3)$ & 626 & $(22.1)$ \\
\hline & $35-44$ & 61 & $(12.6)$ & 337 & $(11.9)$ \\
\hline & $45-54$ & 37 & $(7.6)$ & 233 & $(8.2)$ \\
\hline & $55-64$ & 40 & $(8.3)$ & 179 & $(6.3)$ \\
\hline & $65+$ & 31 & $(6.4)$ & 140 & $(4.9)$ \\
\hline & total & 484 & & 2,839 & \\
\hline & Missing & 26 & $(5.1)$ & 0 & $(0.0)$ \\
\hline \multirow[t]{6}{*}{ Gender } & Male & 120 & $(29.3)$ & 954 & $(33.6)$ \\
\hline & Female & 289 & $(70.7)$ & 1,185 & $(66.4)$ \\
\hline & total & 409 & & 2,839 & \\
\hline & $\begin{array}{l}\text { Recorded as "completing for } \\
\text { someone else" }\end{array}$ & 26 & $(5.1)$ & $\mathrm{N} / \mathrm{A}$ & $\mathrm{N} / \mathrm{A}$ \\
\hline & Other/prefer not to answer & 75 & $(14.7)$ & $\mathrm{N} / \mathrm{A}$ & $\mathrm{N} / \mathrm{A}$ \\
\hline & Missing & 0 & $(0.0)$ & 0 & $(0.0)$ \\
\hline \multirow{4}{*}{$\begin{array}{l}\text { Tried to see a GP } \\
\text { before }\end{array}$} & Yes & 343 & $(67.3)$ & 1,642 & $(57.8)$ \\
\hline & No & 167 & (32.8) & 1,197 & $(42.2)$ \\
\hline & total & 510 & & 2,839 & \\
\hline & Missing & 0 & $(0.0)$ & $\mathrm{N} / \mathrm{A}$ & N/A \\
\hline
\end{tabular}

$\star \star \star *$ Insert Table $1 * \star \star$

\section{Patient Satisfaction with the Service and its Delivery}

Figure 2 presents a breakdown of patient satisfaction with different elements of the STTT service and its delivery (full data included in Supplementary Table 2). Overall, 501 patients (98.2\%) were satisfied with the service and 502 (98.4\%) stated they would recommend the service to others. A total of 506 patients $(99.2 \%)$ agreed or strongly agreed that the pharmacists explained the aims of the service well, and 505 (99\%) were satisfied with how the pharmacist checked whether they needed a throat swab. All except one of those patients who stated they needed a swab $(n=433)$ were satisfied with how this was taken, and $405(92.9 \%)$ of them agreed or strongly agreed that the results of the examination reassured them about their condition. All except three of those patients who stated they did not need a swab $(n=97)$ agreed or strongly agreed that the results of the examination 
reassured them about their condition. 506 patients (98.8\%) agreed or strongly agreed that they had the opportunity to raise questions or concerns related to the service.

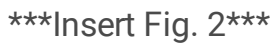

\section{Reported Service Outcomes}

Regardless of whether patients needed a swab or not, 494 out of 510 patients agreed or strongly agreed that at the end of the consultation they felt confident with managing their condition (mean: 4.75, SD: 0.56) (Fig. 2). Of the 487 patients that responded to the question "if test needed, I got an antibiotic from the pharmacy today", 164 (34\%) patients stated they received an antibiotic supply from the pharmacy, and 230 (47\%) stated they did not; 93 stated non applicable (i.e. a swab and a subsequent point-ofcare test was not needed). Similar patterns of response to confidence about managing sore throat and satisfaction with the service were seen in patients who did/did not receive an antibiotic, although patients who did not require a test or who required a test but did not receive an antibiotic were less likely to strongly agree (Table 2).

\section{Table 2}

Patient confidence and satisfaction with the Sore Throat Test and Treat (STTT) service by antibiotic supply status

\begin{tabular}{|c|c|c|c|c|}
\hline \multirow[b]{2}{*}{$\begin{array}{l}\text { Inow feel more confident about managing my sore } \\
\text { throat }(n=510)\end{array}$} & \multicolumn{3}{|c|}{$\begin{array}{l}\text { If test needed, I got an antibiotic supply from the } \\
\text { pharmacy today }(n=487)\end{array}$} & \multirow{2}{*}{$\begin{array}{l}\text { Missing } \\
\text { values } \\
(n=23)\end{array}$} \\
\hline & $\begin{array}{l}\text { Yes } \\
(n=164,34 \%)\end{array}$ & $\begin{array}{l}\text { No } \\
(n=230,47 \%)\end{array}$ & $\begin{array}{l}\text { Test not needed } \\
(n=93,19 \%)\end{array}$ & \\
\hline Strongly disagree $(n=3)$ & $0(0.0 \%)$ & $3(1.3 \%)$ & $0(0.0 \%)$ & $0(0.0 \%)$ \\
\hline Disagree $(n=0)$ & $0(0.0 \%)$ & $0(0.0 \%)$ & $0(0.0 \%)$ & $0(0.0 \%)$ \\
\hline Neither $(n=13)$ & $1(0.6 \%)$ & $8(3.5 \%)$ & $3(3.2 \%)$ & $1(4.3 \%)$ \\
\hline Agree $(n=90)$ & $13(7.9 \%)$ & $49(21.3 \%)$ & $20(21.5 \%)$ & $8(34.8 \%)$ \\
\hline Strongly agree $(n=404)$ & $150(91.5 \%)$ & $170(73.9 \%)$ & $70(75.3 \%)$ & $14(60.9)$ \\
\hline \multicolumn{5}{|l|}{ I am satisfied with the STTT service $(n=510)$} \\
\hline Strongly disagree $(n=4)$ & $0(0.0 \%)$ & $4(1.7 \%)$ & $0(0.0 \%)$ & 0 \\
\hline Disagree $(n=1)$ & $0(0.0 \%)$ & $1(0.4 \%)$ & $0(0.0 \%)$ & 0 \\
\hline Neither $(n=4)$ & $0(0.0 \%)$ & $3(1.3 \%)$ & $1(1.1 \%)$ & 0 \\
\hline Agree (70) & $11(6.7 \%)$ & $38(16.5 \%)$ & $16(17.2 \%)$ & $5(21.7 \%)$ \\
\hline Strongly agree $(n=431)$ & $153(93.3 \%)$ & $184(80.0 \%)$ & 76 (81.7\%) & 18 (78.3\%) \\
\hline
\end{tabular}

\section{Health-seeking Behaviour}

A total of 343 out of 510 patients $(67.3 \%)$ tried to see a GP and 373 out of $510(73.1 \%)$ knew that they could get an antibiotic from the pharmacy before attending a consultation in the pharmacy. After completion of the service, 504 out of 510 patients (98.8\%) stated that they would return to the pharmacy instead of trying to see a GP for subsequent sore throat symptoms.

\section{Free-text Comments}

A total of 242 patients added a free text comment in the survey. Content analysis in relation to satisfaction returned a total of 401 occurences of terms such as "excellent/amazing/brilliant/great/very good/grateful/happy/impressed $(n=176)$, helpful $(n=40)$, professional ( $n=28)$, comfortable/efficient/painless/thorough $(n=28)$, convenient/easier than GP $(n=54)$, fast $(n=37)$, informative $(n=19)$, thank $(n=20)$ ". Inductive analysis revealed 3 themes: convenience and accessibility; professionalism of 
pharmacy team; perceived value (Fig. 3). Table 3 summarises representative quotes from each theme and the respective subthemes. 
Table 3

Themes, subthemes and representative quotes as arising from inductive thematic analysis of the free-text comments in patient experience surveys.

\begin{tabular}{|c|c|c|}
\hline Theme & Subthemes & Representative quotes (survey number) \\
\hline $\begin{array}{l}\text { 1. Convenience } \\
\text { and } \\
\text { accessibility }\end{array}$ & $\begin{array}{l}\text { Increased access and } \\
\text { convenience }\end{array}$ & $\begin{array}{l}\text { "Very good service, doctors were fully booked so helped my daughter } \\
\text { massively" S5 } \\
\text { "Very convenient and helpful. Thank you." S98 } \\
\text { "Fast, easier than using GP" S27 } \\
\text { "Great service, was a lot quicker than waiting for GP" S32 } \\
\text { "Fantastic service and support in my local community and available outside } \\
\text { GP hours." S140 } \\
\text { "Fantastic. Went to doctor's = was sent here. I was a bit reluctant. Seen at } \\
\text { 9am. Checked, assessed and walked away with medication before } 9.30 \text {. } \\
\text { Pharmacist really made me feel at ease. Thank you." S142 } \\
\text { "Much easier than waiting 1-2 hours in the surgery or having to go to out of } \\
\text { hours." S195 }\end{array}$ \\
\hline & $\begin{array}{l}\text { Inconsistent } \\
\text { commissioning and } \\
\text { logistical challenges }\end{array}$ & $\begin{array}{l}\text { "...The surgery, [redacted], referred me to [redacted] pharmacy: no pharmacist } \\
\text { today. They referred me to [redacted] - no pharmacist. Referred then to } \\
\text { [redacted], cost road [sic], car drive away, no pharmacist. Returned to surgery, } \\
\text { referred to [redacted], two towns away. Throat swab taken this is totally } \\
\text { ridiculous, expensive, huge wage of time and I am too ill to do this. Stop this } \\
\text { immediately until there is one system with all pharmacists leave on it for } \\
\text { nearby, workable pharmacies. The pharmacist when found was great but } \\
\text { really, 4th one is terrible." S375 }\end{array}$ \\
\hline
\end{tabular}

Incomplete/inappropriate referral from GP surgeries

"My Drs receptionist should have advised me on where to go as I tried 3 other pharmacies before this one! However excellent and convenient service." S102 "After trying 2 other pharmacists I found [name of pharmacy]..."S250

Lack of awareness for

"...Need to promote better as didn't know this service was available." S140 the service "A wonderful service which I know nothing about until I phoned the surgery to try to get an appointment this pm and was told that this existed" S358

2.

Professionalism of pharmacy

team
"Professional manner, full explanation of procedure." S40

"Very impressed with the service I received. The pharmacist was very thorough and made me feel at ease." S83

"The pharmacist was very welcoming, explaining the entire process and ensured I was happy/comfortable throughout." S 86

"The pharmacy was brilliant from start to finish with my daughter (7 years old), would recommend this pharmacy and treatment to anyone with children. My child was very happy to have the test and get antibiotics. The lady went beyond to make my child happy and comfortable." S94

"Masks/gloves could have been worn. I was aware I was breathing into the pharmacist's face. S90

"Amazing service - reassured me with the test and it was quick and easy very, very impressed" S41

"Received a result swiftly and was certain it was accurate" S54

"...This service enabled me to go back to the GP with the knowledge that I wasn't wasting his time." S58

"Excellent service, attended due to no voice rather than "simple throat". Would have waited another day before a GP appointment - simply wanted clarification that a viral infection." S78

Education around antimicrobial stewardship
"I think this service is a brilliant idea especially that they take a swab to make sure whether antibiotics are needed." S16

"I was so grateful for the service I received. My sore throat and cough was identified as a virus. So no medication was given. Excellent service." S97

"Referral from locum GP to chemist. Virus or bacterial infection? The chemist is a useful and efficient service. This will prevent visits to GPs and reduce demands for unnecessary antibiotics..." S166

"I had tonsillitis, tried to see a GP but was refused and told to go to pharmacist. He told me just take paracetamol and plenty of fluids and rest. I will never use this service again because I needed antibiotics but was told no, within 3 days I had fluid on my left lung, so a fully developed chest infection meaning I needed antibiotics." S306

"Went to pharmacy, test negative, had to go to doctors straight after test, saw nurse, given antibiotics." S463 


\begin{tabular}{|c|c|c|}
\hline Theme & Subthemes & Representative quotes (survey number) \\
\hline & $\begin{array}{l}\text { Pharmacists providing } \\
\text { services in primary care }\end{array}$ & $\begin{array}{l}\text { "This service will aid Doctor's surgeries and help patients with their } \\
\text { illness/diagnosis quickly - should be available everywhere" S45 } \\
\text { "Very professional. I believe the scheme could be rolled out and offer more } \\
\text { common ailments that the ones included at the moment." P145 } \\
\text { "... I feel if I had not been treated at the chemist I would have to [go to ] A\&E as } \\
\text { the Doctors surgery was closed till Tues (Bank Holiday) [Tuesday after a Bank } \\
\text { Holiday Monday] and my condition would have worsened..." S451 } \\
\text { "The only reason I would not return to the pharmacy next time is because it is } \\
15 \text { minutes drive away instead of } 2 \text { min to the GP. But if my local pharmacy } \\
\text { did the scheme I would definitely go there instead of to the GP surgery." S438 } \\
\text { "Great idea. Just need to think about the impact for the pharmacist." S47 }\end{array}$ \\
\hline
\end{tabular}

***Insert Fig. $3^{* * *}$

***Insert Table $3^{\star \star \star *}$

\section{Convenience and Accessibility}

Patients discussed how the service being available even out of GP opening times without the need to book in advance and make an appointment increased their access to services. At the same time, timely access minimised disruption to patients' lives.

"It was so convenient to call and consult with the pharmacy without having to make an appointment." S84

"..very happy with it [service] seen quickly and reduced time off school/work" S119

Even though the service was overwhelmingly accepted as convenient, practical challenges in pilot sites and inconsistent commissioning of the service were perceived by some patients as factors that limit the usefulness and access to specific cohorts of patients.

"The idea on paper is a good idea but practically (see below.) There was a lot of "running around + inconvenience". I visited the doctors, then the 1st chemist but the computer wasn't working, the second chemist couldn't do it but was very helpful, finally ended up 10 min away - 4th visit of morning who took swab. All chemists were very friendly and helpful, but it was so inconvenient. I feel really sorry for older age groups + people with no transport." S439

Inappropriate referral from GP surgeries in three cases was identified as a challenge, in particular when patients outside of service specification criteria were referred, or patients were directed to pharmacies not piloting STTT.

“They [staff at GP reception] didn't even ask me how old my daughter is...[had to go] all the way to the pharmacy where I was told she can't have it [STTT consultation] as she [my daughter] is only 3. I mean he [pharmacist] still helped us but no test or anything." S403

Many patients discussed how lack of publicity of the service limits patient engagement with them. It was thought that pharmacy services need to be better promoted to the general public.

"All services offered at a pharmacy need MUCH more publicity. I work for the NHS and did not realise what options were available." S1

Professionalism of Pharmacy Team

Patients felt very strongly about the professionalism exhibited by the team in the pharmacy, commenting on how this made them feel comfortable and at ease about the whole process. Only one patient commented on their preference for gloves being worn.

"Pharmacist and pharmacy could not have been more helpful or friendly. The service was quick and efficient and comfortable. Amazing!" S143

Perceived Value of the Service 
Patients identified that the structure of the service, including the point-of-care test, increased their confidence in the treatment outcome, reduced the diagnostic uncertainty and reassured them about their condition. Many patients added comments discussing viral vs. bacterial infections, confirming how the service supported education around antimicrobial stewardship. A small number of patients demonstrated a lack of understanding of the principles of antimicrobial stewardship.

"...my sore throat and cough was identified as a virus. So no medication was given..." S97

"I will never use this service again because I needed antibiotics but was told no, within 3 days I had fluid on my left lung, so a fully developed chest infection meaning I needed antibiotics." S306

There was a general belief that management of not only uncomplicated sore throat but other minor ailment services should be transferred to community pharmacies and rebalance the workload in primary care to ease pressure on GPs and out-of-hour services. Pharmacists were perceived as the right healthcare professionals to be responsible for this.

"I think this [service] is a great idea, no inconvenience to the patient and eases pressure on the GP. Informative and friendly service by the pharmacist." S34

"For the past 6 months it is so hard to get into the doctors you can never get in. Pharmacist always happy to see if he can help me and I found he actually helped me out." S127

Three patients reflected on requirements to be met for future extended services from community pharmacies, such as consideration of community pharmacists' workload and consistent availability of services :

“"'The pharmacy I attended is extremely busy and there were only 2 pharmacists working and they were extremely stressed having to do prescriptions and see the people with throat problems. If this is being done then more staff should be available to do the tests." S144

\section{Discussion}

To the authors' knowledge, this is the first study internationally to explore patient views of a STTT service delivered in community pharmacies. We examined data from patient experience surveys to evaluate whether a pilot of an NHS funded pharmacy STTT service in the UK was acceptable and influenced patients' health-seeking behaviour towards requesting help from a community pharmacist, rather than a GP, when having a sore throat in the future.

Data from the first five months of the STTT service suggest that it is highly acceptable to patients, and that this acceptability is not dependent on being supplied antibiotics. Previous research has illustrated how patient expectations of an antibiotic have been managed by non-medical prescribers when treating respiratory tract infections [19]. Even though $43 \%$ of patients seen by a nonmedical prescriber expected an antibiotic, this did not influence the strategies utilised by the healthcare professional. In contrast, they employed non-antibiotic, patient-centred approaches focussing on patient education, reassurance and physical examination. As a result, $96 \%$ of patients included in the study were satisfied with the consultation. This current study illustrates how patients also received increased education around antimicrobial stewardship (AMS), reaffirming the value of pharmacists in the global fight against antimicrobial resistance, as reported by Jones et al. [20]. The protected patient time and increased training provided to pharmacists as part of the service may have contributed to promoting appropriate use of antibiotics; only a small number of patients left comments that were indicative of lack of understanding of the principles of AMS.

Accessibility of the pharmacy and convenience was mentioned multiple times, mainly as an enabler for patients to access the service. Only one patient identified it as a challenge, comparing it to the shorter distance to the GP practice. Todd et al. discussed in 2014 how the majority of the population in England can access a community pharmacy within a 20-minute walk and how access is greater in areas of highest deprivation [21]. In their 2015 paper, the same authors further conclude that even though the vast majority of the population live within a 20 min walk of a GP premises, more people live within a 20 min walk of a community pharmacy, compared with GP premises [22]. Improved access to services and hence providing more options for patients contributes to redirecting management of uncomplicated conditions from primary care to community pharmacies, a key aspect in both the NHS England Long Term Plan and the Welsh Government's vision for 'A Healthier Wales' [1-2], with implications for the

Page 10/18 
commissioning of future services. A recent document setting the pharmacy profession's future vision in Wales included recommendations on a number of strategies to support the community pharmacy workforce to deliver a range of extended services, including integration of an independent prescriber in every pharmacy team by 2030 [23].

In our sample population, which is highly representative of the total population who consulted their pharmacist for STTT, two thirds tried to see a GP before attending a STTT consultation. This decision to access a GP as a priority seems to be changing, with all but 6 patients reporting that they will return to the pharmacy next time they have symptoms of sore throat. Even though this is patient self-reported behaviour and needs to be validated by tracking patients across the system, it is an indication of the service's potential success in shifting health seeking behaviour. This finding can be contextualised in light of results of a systematic review in patient and public perspectives on community pharmacies [4]. The authors identified patients' reduced awareness of extended pharmacy services which led to low utilisation of these and reluctance in supporting pharmacists to carry out extended roles. This was linked to concerns over pharmacists' knowledge and skills outside of the traditional dispensing and medicines advice roles and a general preference for GPs over pharmacists, regardless of the service provided. However, patient and public attitudes were influenced by frequency of service usage and the perceived impact or benefit from using these services, which is what we observed in our study. A recent cross-sectional survey looking at usage of community pharmacy services in England by patients with long-term respiratory conditions further reiterates our findings: most patients in the survey preferred to use GP practices for diagnostic services, but preference was associated with services previously accessed at the pharmacy [24]. Both studies identified professionalism of the whole pharmacy team and timeliness of consultations as features that enhance patient and public use of pharmacy services, in addition to convenience and ease of access, which were also identified by patients in our study.

Patients discussed perceived barriers to further roll-out, including low awareness for the service, inconsistent provision and availability, inappropriate referrals by GP teams, and consideration of the increased workload for pharmacists. These barriers have been discussed elsewhere in the literature. Despite patients overall being broadly positive for pharmacists providing extended services, awareness is low [4,24-25]. Increased collaboration between GPs and pharmacists has been identified as key to successful implementation and integration of new pharmacy services, with studies reporting these services not always perceived as beneficial or useful from the GPs' point of view [26-27].

Limitations:

The response rate is based on the assumption that all patients consulting for a sore throat that fit the criteria for the STTT service were given a survey by the pharmacist. Even though literature suggests that the use of both paper and online methods increases the response rate [28], this study only received paper copies of responses and as such the response rate was relatively low. We accounted for the low response rate that may lead to suboptimal representation for some patient groups, by examining baseline characteristics and concluding that completed surveys were returned from a representative sample of the total population who had completed STTT consultations in pharmacies during the same time period in terms of age and gender [29], but not in terms of having tried to see a GP before attending the pharmacy. Even though not all assumptions/conditions were met for a chi-squared test between antibiotic supply and confidence with managing the condition after the consultation or satisfaction with the service, we completed descriptive statistics to examine a possible link.

Patient and Public Involvement (PPI) Reflections:

\section{Public Representative}

I have been involved in a number of research projects where the researchers were experienced in PPI however, in this project, the leads of this research team had little or no previous experience of it. Although some aspects of best practice in PPI that are expected in research projects these days were not there, the team engaged with the public representatives to get a better understanding of what needed to be done in their future projects. Not only has this led to a positive experience for me on this project but has also led to discussions about future collaborations with the research team members.

Research Team Member

Prior to this project, I had limited experiences with involving patients in research design and methodology, and I had no real concept of the potential benefits. Experienced team members guided me to reflect on the standards for patient involvement in

Page $11 / 18$ 
research and effectively engage with public representatives. Their input has brought new insights to all stages of this project and has led to wider collaborations where their support has been invaluable.

\section{Conclusions}

This first ever study on patient acceptability of NHS funded sore throat test and treat services in the UK, revealed high levels of patient satisfaction with the service, the way it was delivered by community pharmacists and the increased choice of options for sore throat symptom management it offered. Whilst this research can only discuss patients' self-reported future behaviour, the stated intentions of the patients indicate a potential shift in health-seeking behaviour towards a pharmacist instead of the GP. This has important implications in supporting the long term plan of the governments in Wales and England to redirect management of uncomplicated conditions from GPs to pharmacies. To enable the desired behaviour change, factors that are important to patients have been highlighted in this research. Coordinated efforts to increase awareness of pharmacy services; effective restructuring of pharmacists' workload to accommodate capacity for extended services as part of routine care in the NHS, increasing pharmacist motivation and willingness to engage; and effective integration and communication of any new pharmacy services within referral pathways across the whole of primary care are all necessary. Results of this study were presented to policy-makers and have influenced the decision to roll out the service nationally, across selected sites that make up more than $50 \%$ of community pharmacies in Wales.

\section{Abbreviations}

AMS Antimicrobial Stewardship

CAS Common Ailment Scheme

CP Community Pharmacist

GP General Practitioner

NHS National Health System

NWIS NHS Wales Informatics Service

PGS Patient Group Direction

STTT Sore Throat Test and Treat

UK United Kingdom

\section{Declarations}

\section{Ethics approval and consent to participate}

The study was registered with the Research and Development departments in Betsi Cadwaladr (ref:18/176) and Cwm Taf Morgannwg (ref:CT/937/18) Local University Health Boards.

\section{Consent for publication}

Not applicable

\section{Availability of data and materials}

The datasets analysed during the current study are available from the corresponding author on reasonable request. 
The authors declare that they have no competing interests.

\section{Funding}

No funding has been obtained for this study.

\section{Authors' contributions}

$\mathrm{EM}, \mathrm{AE}, \mathrm{CW}$ and $\mathrm{RD}$ conceptualised the study. EM designed and managed the study, coordinating data collection and took lead on manuscript preparation and final submission. LH and LG shared inputting the data on Jisc database. EM completed a validation of the data input. EM, RCJ, HA, AM and IA were involved in data analysis interpretation. AM and IA led the drafting of the lay summary. All authors were involved in reviewing versions of the manuscript.

\section{Acknowledgements}

We would like to thank all the community pharmacists who supported this research by distributing the patient experiences surveys. We would also like to thank Haseeb Fazili, graphic designer at NHS Wales Informatics Service, for designing Figure 1.

\section{Plain English Summary}

This study focuses on patients' experience of a pilot service for testing and treating sore throats where the consultation took place in a pharmacy rather than a GP surgery. It looked at whether the patients felt that this approach was acceptable and if their experience of the service would affect where they would seek support for sore throats in the future. The study took place in Wales between November 2018 and May 2019.

The experiences of the patients that used the service were gathered using a survey developed in partnership with public representatives recruited from the Lay Faculty of the School of Pharmacy and Pharmaceutical Sciences at Cardiff University. The first part of the survey comprised a short series of set questions and the second part of the survey allowed the patients to comment, in their own words, on their experiences of the service they received.

A total of 510 surveys were completed from the 2,839 consultations that took place, a response rate of $18 \%$. The results showed that 501 patients $(98 \%)$ were satisfied with the service and stated they would recommend the service to others. The results not only confirmed high levels of patient satisfaction with the new service but also the way it was delivered and the increased choice of options for sore throat symptom management it offered.

\section{References}

[1]. Welsh Government. A Healthier Wales. 2018 https://gov.wales/sites/default/files/publications/2019-10/a-healthier-walesaction-plan.pdf. Accessed 20 Jan 2020.

[2]. NHS. The NHS long term plan. 2019. https://www.longtermplan.nhs.uk/. Accessed 20 Jan 2020.

[3]. Watson MC, Ferguson J, Barton GR, Maskrey V, Blyth A, Paudyal V, et al. A cohort study of influences, health outcomes and costs of patients' health-seeking behaviour for minor ailments from primary and emergency care settings. BMJ Open. 2015;5:e006261. http://dx.doi.org/10.1136/bmjopen-2014-006261

[4]. Hindi A, Schafheutle E, Jacobs S. Patient and public perspectives of community pharmacies in the United Kingdom: A systematic review. Health expectations: an international journal of public participation in health care and health policy. 2017 Nov 8;1. https://doi.org/10.1111/hex.12639

[5]. Craig P, Dieppe P, Macintyre S, et al. Developing and evaluating complex interventions: new guidance: MRC, 2008 https://mrc.ukri.org/documents/pdf/complex-interventions-guidance/. Accessed 20 Jan 2020.

Page $13 / 18$ 
[6]. Buss V, Deeks L, Shield A, Kosari S, Naunton M. Analytical quality and effectiveness of point-of-care testing in community pharmacies: A systematic literature review. Res Social Adm Pharm. 2019;15:483-495.

[7]. New free throat screening service launched. Health Central. 2019 https://healthcentral.nz/new-free-throat-screening-servicelaunched/. Accessed 20 Jan 2020.

[8]. Rapid sore throat test. Hickey's Pharmacy. https://www.hickeyspharmacies.ie/services/rapid-sore-throat-service/. Accessed 20 Jan 2020.

[9]. Finch I. Superdrug launches free sore throat service in more than 200 branches. Chemist and Druggist. Dec 2018 https://www.chemistanddruggist.co.uk/news/superdrug-launches-free-sore-throat-service-over-200-branches. Accessed 20 Jan 2020.

[10]. Thornley T, Marshall G, Howard P, Wilson AP. A feasibility service evaluation of screening and treatment of group A streptococcal pharyngitis in community pharmacies. J Antimicrob Chemother. 2016;71(11):3293-9

[11]. Mantzourani E, Hicks R, Evans A, Williams E, Way C, Deslandes R. Community Pharmacist Views On The Early Stages Of Implementation Of A Pathfinder Sore Throat Test And Treat Service In Wales: An Exploratory Study. Integr Pharm Res Pract. 2019 Nov 11;8:105-113

[12]. UK Standards for Public Involvement November 2019. https://sites.google.com/nihr.ac.uk/pi-standards/home

[13]. Stockmeyer NO. Using Microsoft Word's Readability Program. Michigan Bar Journal.

2009;88:46-7.

[14]. Boynton PM, Greenhalgh T. Selecting, designing, and developing your questionnaire. BMJ. 2004;328:1312-5.

[15]. National Health Service (NHS). Children and young people: Consent to treatment.

2019. https://www.nhs.uk/conditions/consent-to-treatment/children/. Accessed 20 Jan 2020.

[16]. Dillman DA, Smyth JD, Christian LM. Internet, Phone, Mail and Mixed-Mode Surveys. 4th ed. Hoboken, New Jersey: John Wiley \& Sons, Inc; 2014.

[17]. Greenlaw C, Brown-Welty S. A Comparison of Web-Based and Paper-Based Survey Methods. Eval Rev. 2009;33(5):464-80.

[18]. Office for National Statistics. Language in England and Wales: 2011. 2013.

https://www.ons.gov.uk/peoplepopulationandcommunity/culturalidentity/language/articles/languageinenglandandwales/201303-04\#welsh-language. Accessed 16 Jan 2020.

[19]. Courtenay M, Rowbotham S, Lim R, Deslandes R, Hodson K, MacLure K, Peters, S, Stewart D. 2017. Antibiotics for acute respiratory tract infections: a mixed-methods study of patient experiences of non-medical prescriber management. BMJ Open. 2017;7:e013515. http://dx.doi.org/10.1136/bmjopen-2016-013515

[20]. Jones LF, Owens R, Sallis A, et al. Qualitative study using interviews and focus groups to explore the current and potential for antimicrobial stewardship in community pharmacy informed by the Theoretical Domains Framework. BMJ Open.

2018;8:e025101. http://dx.doi.org/10.1136/bmjopen-2018-025101

[21]. Todd A, Copeland A, Husband A, Kasim A, Bambra C. 2014 The positive pharmacy care law: an area-level analysis of the relationship between community pharmacy distribution, urbanity and social deprivation in England BMJ Open 4:e005764. http://dx.doi.org/10.1136/bmjopen-2014-005764

[22]. Todd A, Copeland A, Husband A, et al Access all areas? An area-level analysis of accessibility to general practice and community pharmacy services in England by urbanity and social deprivation BMJ Open 2015;5:e007328. http://dx.doi.org/10.1136/bmjopen-2014-007328

[23]. Welsh Pharmaceutical Committee. Pharmacy: Delivering a Healthier Wales. The Royal Pharmaceutical Society. https://www.rpharms.com/Portals/0/RPS\%20document\%20library/Open\%20access/Policy/Pharmacy\%20Vision\%20English.pdf?

Page $14 / 18$ 
ver=2019-05-21-152234-477. Accessed: 16 Jan 2020.

[24]. Hindi AMK, Schafheutle El, Jacobs S Applying a whole systems lens to the general practice crisis: cross-sectional survey looking at usage of community pharmacy services in England by patients with long-term respiratory conditions BMJ Open 2019;9:e032310. http://dx.doi.org/10.1136/bmjopen-2019-032310

[25]. Leav VM, Corlett SA< Rodgers RM Workload and its impact on community pharmacists' job satisfaction and stress: a review of the literature. Int J Pharm Pract. 2012 Aug;20(4):259-71.

[26]. Hindi, A, Jacobs, S \& Schafheutle, E 2019, 'Solidarity or Dissonance? A Systematic Review of Pharmacist and GP Views on Community Pharmacy Services in the UK', Health Soc Care Comm. 2018 Jul;27(3):565-598.

[27]. Bradley F, Ashcroft DM, Noyce PR. Integration and differentiation: a conceptual model of general practitioner and community pharmacist collaboration. Res Social Adm Pharm 2012;8:36-46.

[28]. Greenlaw C, Brown-Welty S. A Comparison of Web-Based and Paper-Based Survey Methods. Eval Rev. 2009;33(5):464-80.

[29]. Gayet-Ageron A, Agoritsas T, Schiesari L, Kolly V, Perneger TV. Barriers to participation in a patient satisfaction survey: who are we missing? PLoS One. 2011;6(10):e26852. http://dx.doi.org/10.1371/journal.pone.0026852

\section{Figures}




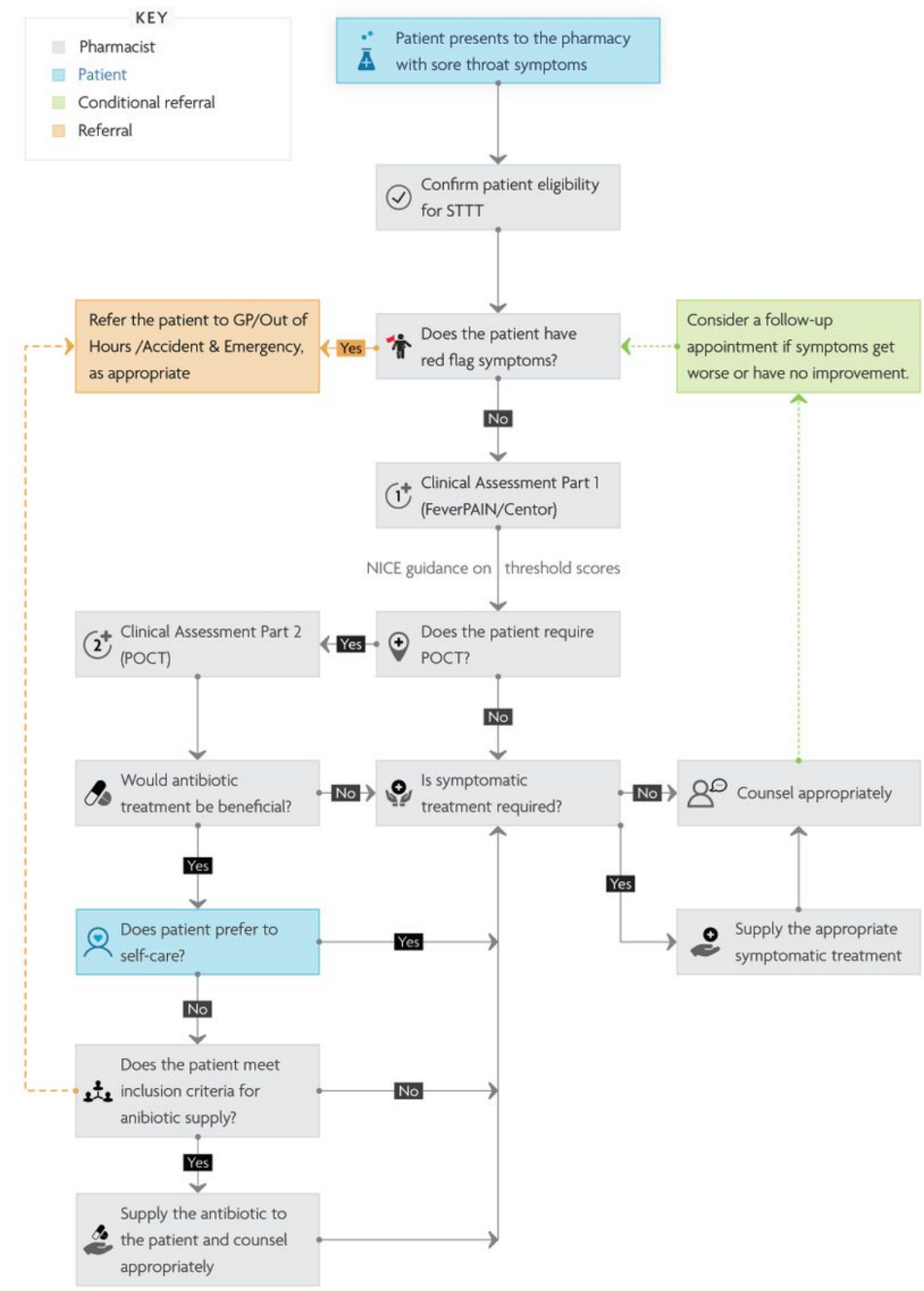

\section{Figure 1}

Patient journey through the Sore Throat Test and Treat (STTT) community pharmacy service 


\section{Patient satisfaction with the STTT service}

I would recommend the service to others $(n=510)$

I am satisfied with the service $(n=510)$

I now feel more confident about managing my sore throat $(n=510)$

I had the opportunity to raise questions or concerns related to the service $(n=510)$

If swab taken - the results of the test reassured me about my condition ( $n=420$ )

If swab taken - I am satisfied with how the pharmacist took the swab $(n=433)$

If no swab needed - the results of the examination reassured me about my condition $(n=97)$

I am satisfied with how the pharmacist checked whether I needed a throat swab $(n=510)$

The pharmacist explained well the aims of the service to me $(n=510)$
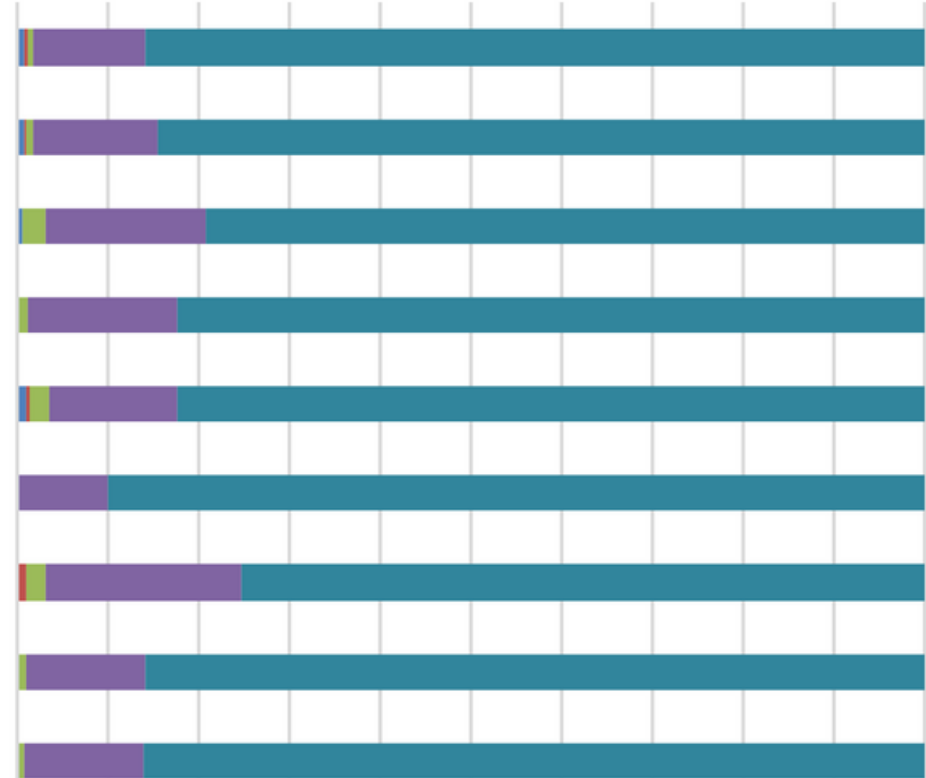

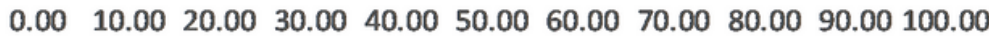

Percentage

\section{घ Strongly Disagree $\quad$ Disagree $\quad$ Neither Agree or Disagree $\quad$ Agree $\quad$ Strongly Agree}

\section{Figure 2}

A bar chart showing the percentage patient satisfaction in relation to different aspects of the Sore Throat Test and Treat (STTT) service and its delivery

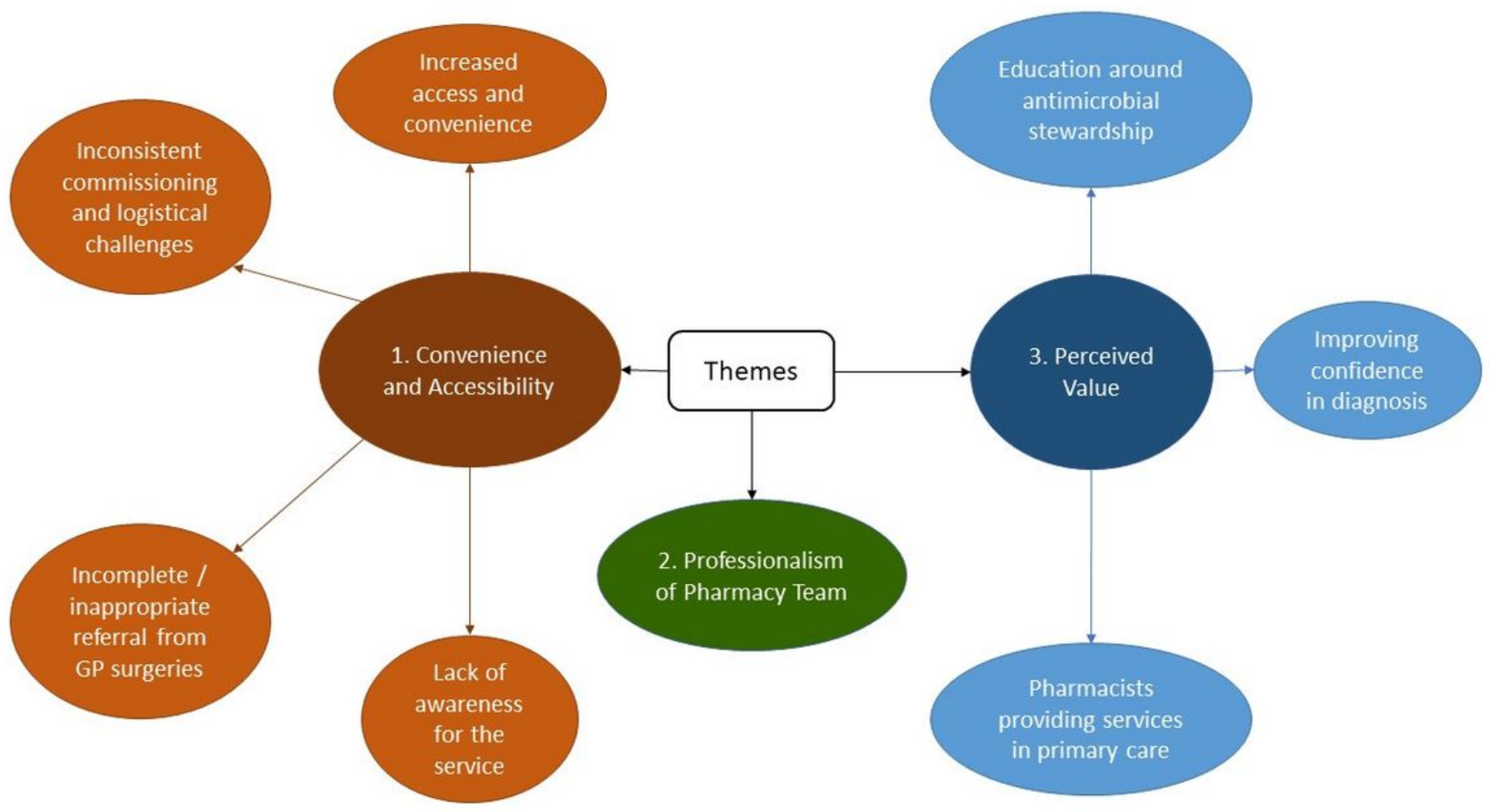


Figure 3

An overview of the themes, as arising from inductive analysis of free-text comments added in patient experience surveys for Sore Throat Test and Treat (STTT)

\section{Supplementary Files}

This is a list of supplementary files associated with this preprint. Click to download.

- SupplementaryFigure1ExitquestionnaireEnglish.pdf

- SupplementaryTable1GRIPP2Shortform.docx

- SupplementaryTable2.docx

- SupplementaryFigure2ExitquestionnaireWelsh.pdf 